\title{
FLEXISECURITY E A GARANTIA DO TRABALHO EM TEMPOS DE CRISE ECONÔMICA: UMA POSSIBILIDADE JURÍDICA OU UMA REALIDADE ATUAL?
}

\author{
Flávia de Paiva Medeiros de Oliveira ${ }^{1}$ \\ Rogério Coutinho Beltrão ${ }^{2}$
}

\begin{abstract}
RESUMO: Esse artigo busca apresentar a teoria da flexisegurança ou flexisecurity, a qual busca concretizar os postulados da flexibilização e da segurança e proteção do trabalhador. Apesar da inegável dificuldade de conceituação e aplicação da teoria de forma concreta, procura-se analisar a flexibilização do direito do trabalho em uma perspectiva de amoldamento à realidade de crise econômica vivenciada em diversos países, inclusive, no Brasil. Para isso, no presente estudo será adotado o método dedutivo através da análise documental, a fim de compreender como a flexisecurity influencia na tendência atual e globalizada de regular as relações laborais.
\end{abstract}

Palavras-Chave: Flexisegurança; Reforma Trabalhista; Trabalho Decente; Crise Econômica.

\section{THE FLEXISECURITY AND THE GUARANTEE OF LABOOR IN PERIOD OF ECONOMIC CRISIS: A LEGAL POSSIBILITY OR CURRENT REALITY?}

\begin{abstract}
This paper aims to explain the theory of flexisecurity, which is aimed to accomplish the flexibility and the safety and worker protection. Despite the undeniable difficulty of conceptualizing and applying the theory in a concrete way, it seeks to analyze a flexibilization of the labor right in a perspective of adaptation to the reality of economic crisis experienced in several countries, including Brazil. For this, this study will adopt the deductive search method through documentary analysis, in order to understand the theory of flexisecurity in the current and globalized way of regulate labor relations.
\end{abstract}

Keywords: Flexicurity; Labor Reform; Decent Work; Economic Crisis.

\footnotetext{
1 Possui graduação em Direito pela Universidade Estadual da Paraíba (1999), mestrado em Direito pela Universidade Federal do Ceará (2001) e doutorado em Direito do Trabalho e Previdência Social - Univeritat Valencia-Espanha (2005). Atualmente é professora da Universidade Estadual da Paraíba e do Centro Universitário João Pessoa (UNIPE); com e-mail flaviadepaiva@ hotmail.com; e endereço postal na Rua Elias Asfora, 241 - A, centro, Campina Grande - PB

${ }^{2}$ Graduado em Direito pela Universidade Federal da Paraíba, Pós-Graduado em Direito e Processo do Trabalho pela Faculdade Damásio, Mestrando em Direito pelo Centro Universitário de João Pessoa - UNIPE; com e-mail rogerio.beltrao@rb-advs.com, e endereço postal na Av. Mato Grosso, nº 418, João Pessoa - PB.
} 


\section{INTRODUÇÃO}

O tema da flexibilização das normas trabalhistas volta à pauta de discussão no atual contexto econômico, político e laboral brasileiro em um cenário em que a sociedade é levada a suportar as consequências da crise econômica que apresenta como um dos seus principais efeitos o crescimento do número de desempregados. Nesse contexto, sente-se uma necessidade de criar postos de trabalho, através dos quais se procura dar dinamismo à economia. A criação de postos de trabalho também se apresenta como uma medida que ganha relevo no âmbito internacional, razão pela qual a Organização Internacional do Trabalho (OIT) determinou uma meta numérica que deve ser buscada pelos seus Estados membros no que concerne à geração de postos de trabalho.

A referida Organização, no entanto, deixa claro que a sua preocupação não gira apenas em torno da criação de vagas de trabalho, mas, sobretudo, que tais vagas sejam acompanhadas da devida proteção social e da participação dos sujeitos intervêm na relação laboral, constituindo esse o núcleo do trabalho decente.

A realidade mostra que o atual momento que a sociedade brasileira vive, no qual foi aprovada uma reforma trabalhista que propõe a mitigação de alguns direitos conquistados pelos trabalhadores após anos de luta, vai de encontro à conjuntura internacional consubstanciada na Agenda 2030 para o Desenvolvimento Sustentável, aprovada pela Organização das Nações Unidas (ONU) em 2015, que tem como um dos seus objetivos fomentar a geração de vagas de emprego $^{3}$ que garantam a dignificação do trabalhador por meio de sua inclusão social.

O presente artigo tem como objetivo analisar o instituto da flexissegurança, gestada no Direito Europeu com a finalidade de conciliar as necessidades e anseios antagônicos do mercado e da classe trabalhadora, por meio de medidas que, por um lado, flexibilizam as normas trabalhista em prol da criação de empregos, mas, por outro, confere segurança e proteção aos trabalhadores. A importância da discussão dessa temática se mostra nítida no atual cenário laboral brasileiro, mormente quando se avalia a situação interna em comento com a realidade delineada pelas normas elaboradas pelas organizações internacionais, que propõem que a criação de postos de trabalho não constitui um fim em si mesmo, mas uma parte relevante de uma meta maior que deve ser buscada, qual seja, a sustentabilidade.

Para se alcançar o objetivo proposto, utilizaremos método dedutivo, tendo como ponto de partida premissas gerais, que consistiram na avaliação da dignidade, do trabalho decente e do

\footnotetext{
${ }^{3} \mathrm{O}$ termo aqui foi empregado no seu sentido amplo.
} 
pleno emprego, para, posteriormente, avaliar o caso concreto, a teoria da flexissegurança. Foram feitos levantamentos bibliográficos, tendo sido utilizada a técnica de pesquisa indireta.

A flexibilização de normas trabalhistas deve sempre respeitar os postulados da valorização do trabalho humano e da sua dignidade, do valor social do trabalho, do pleno emprego, entre tantos outros princípios fundamentais que direcionam o direito para proteção do ser-humano, e não do capital, sem, contudo, olvidar que a dinâmica do mercado por diversas vezes precisa de normas flexíveis para o seu desenvolvimento, capazes de acompanhar as necessidades das cadeias produtivas e das relações sociais.

\section{O PRINCIPIO DA DINIGDADE HUMANA, DO TRABALHO DECENTE E DO PLENO EMPREGO COMO GARANTIAS INDERROGÁVEIS DO TRABALHADOR}

A Constituição brasileira de 1988 (CF/1988) deixa claro que o centro do ordenamento jurídico pátrio é a pessoa humana. Nesse sentido, no seu art. $1^{\circ}$, III, erigiu a dignidade da pessoa humana ao patamar de princípio fundamental da República Federativa do Brasil, ao lado dos valores sociais do trabalho e da livre iniciativa. A análise desse dispositivo constitucional denota que a intenção do legislador constituinte era a de conferir mais importância à dignidade do que ao trabalho. Isso porque elencou aquele valor constitucional antes deste, do que resulta o trabalho deve ser encarado como um fator de dignificação da pessoa humana.

Segundo Sarlet (2007, p. 62), a dignidade da pessoa humana deve ser entendida como:

[...] a qualidade intrínseca e distintiva reconhecida em cada ser humano que o faz merecedor do mesmo respeito e consideração por parte do Estado e da comunidade, implicando, neste sentido, um complexo de direitos e deveres fundamentais que assegurem a pessoa tanto contra todo e qualquer ato de cunho degradante e desumano, como venham a lhe garantir as condições existenciais mínimas para uma vida saudável, além de propiciar e promover sua participação ativa e co-responsável nos destinos da própria existência e da vida em comunhão com os demais seres humanos.

O reconhecimento de dignidade ao ser humano lhe outorga a prerrogativa de ser titular de direitos e deveres fundamentais, que funcionam como um limite frente ao Estado e à comunidade que jamais poderão lhe atribuir um trato desumano ou degradante e, ademais, assegura-lhe condições existências mínimas. Se a dignidade da pessoa humana, como princípio fundamental constitucional, antecede o valor social do trabalho e da livre iniciativa resta manifesto que a proibição de trato desumano e degradante, bem como a necessidade de se conferir ao ser humano condições mínimas de existência se estendem também para as relações 
que se estabelecem entre patrão e empregado. Cumpre, ainda, destacar que o trabalho, como valor social, precede a livre iniciativa na topografia constitucional do art. $1^{\circ}$, da CF/1988, pelo que se dessume que aquele valor constitucional não pode ser sacrificado em nome deste. Ao contrário, os dois devem se harmonizar com vistas a garantir que a dignidade seja concretizada.

No dizer de Cecato (2008, p. 178), o trabalho realizado em condições de dignidade é:

[...] meio de provimento de necessidades materiais, morais e emocionais do trabalhador, aí incluídas a auto-estima e a inserção deste na comunidade em que vive. Para além disso, o trabalho é capaz de minorar a vulnerabilidade do trabalhador à violência e à exploração de toda sorte.

A dignidade humana não se harmoniza com a falta de trabalho, sem o qual o ser humano não pode prover a sua existência, o que lhe assegura uma vida com dignidade (LEDUR, 1998, p. 103). No entanto, esse valor constitucional também não se coaduna com o trabalho realizado em condições indignas, que reduzam o ser humano a um tratamento degradante e desumano.

Por essa razão, a OIT reconhece que, uma vez existindo postos de trabalho, faz-se mister que os mesmos atendam a pressupostos de respeito às normas laborais, ao diálogo social e à proteção social. Esses são os pilares sobre os quais se assenta o trabalho decente. Para isso, a Agenda 2030 para o Desenvolvimento Sustentável (ONU, 2015), no seu Objetivo $\mathrm{n}^{\circ} 8$ enumera que a promoção do crescimento econômico inclusivo e sustentável, do emprego e do trabalho decente para todos é uma das metas que deve ser buscada a nível internacional. A própria organização internacional mencionada constatou que, desde 2008, o crescimento do emprego alcançou o patamar médio de $0,1 \%$ (zero, um por cento) ao ano, enquanto que, no período de 2000 a 2007, a média era de 0,9 (zero, nove por cento) ${ }^{4}$. Observa-se, assim, que houve um decréscimo na criação de postos de trabalho, o que é um dos pressupostos para se ter um trabalho decente, pelo que a citada organização reconhece como imperiosa a necessidade de criar trabalhos decentes nos seguintes termos:

Promover el empleo y las empresas, garantizar los derechos en el trabajo, extender la protección social y fomentar el diálogo social son los cuatro pilares del Programa de Trabajo Decente de la OIT, con la igualdad de género como tema transversal. Estos son factores indispensables para hacer avanzar toda la Agenda de Desarrollo Sostenible. El trabajo decente para todos reduce las desigualdades e incrementa la resiliencia. Las políticas elaboradas a través del diálogo social ayudan a las personas

4 Disponível em: <http://www.oit.org/global/topics/sdg-2030/goal-8/lang--es/index.htm>. Acesso em: 02 de agosto de 2017. 
y a las comunidades a hacer frente al cambio climático y, al mismo tiempo, facilitan la transición hacia una economía más sostenible. Y, lo que no es menos importante, la dignidad, la esperanza, y el sentido de justicia social que se derivan de tener un trabajo decente ayudan a construir y mantener la paz social. (OIT, 2017, p. 2).

Nesse contexto, o trabalho decente aparece como um motor de promoção da sustentabilidade, encarada sob o seu viés multidimensional, social, econômico e ambiental, pelo mister a criação de, pelo menos, 600 (seiscentos) milhões de empregos no período 2017/2030. A dificuldade sentida a nível internacional, todavia, não consiste apenas em criar postos de trabalho, mas em garantir que eles sejam sustentáveis, assegurando proteção social ao obreiro, diálogo social, participação na elaboração de normas que lhe dizem respeito, passando, transversalmente, pelo respeito à igualdade e ao meio ambiente do trabalho.

Trata-se, portanto, de uma necessidade de criar postos de trabalho com qualidade, tanto para quem trabalha, quanto o entorno no qual se trabalha com vistas a promover a inclusão social e diminuir a pobreza. Não obstante, a criação de postos de trabalho decentes não é uma tarefa fácil, porque, em geral, esbarra, nos países em desenvolvimento, em uma tendência de reduzir a questão a uma avaliação simplória que consiste em meramente centrar as políticas de crescimento econômico em fazer nascer trabalhos e empregos sem qualquer proteção laboral, diálogo social e participação (OIT, 2017).

A pauta de ações da OIT para o período 2017/2030 deixa patente que a sua preocupação é com criação de postos de trabalho sustentáveis, capazes de garantir a inserção social da pessoa que trabalha e, ao mesmo tempo, reduzir a pobreza.

Essa preocupação é bem mais ampla do que a que foi objeto da Convenção $n^{\circ} 122$ (OIT, 1965), por meio da qual se estabeleceu, no plano internacional, a necessidade de buscar o pleno emprego. Para isso, os Estados membros da OIT devem garantir que haja trabalho produtivo para todas as pessoas aptas a trabalhar e que estão à procura de ocupação; que a escolha pelos postos de trabalho seja livre e que o obreiro tenha a oportunidade de se qualificar, sendo-lhe permitido usar as suas qualificações e seus dons sem qualquer distinção de raça, cor, sexo, religião, opinião política, ascendência nacional ou origem social.

O atual cenário jurídico criado pela conjuntura internacional em torno do trabalho é bem mais amplo do que aquele delineado em 1965, quando se buscava alcançar o pleno emprego, pelo que se pode dizer que a concretização de trabalho decente transcende da órbita empresarial e desemboca na vida social, vez que o que se almeja é criar postos de trabalho nos 
quais os direitos individuais e coletivos do obreiro sejam respeitados, porque isso gera crescimento econômico com inclusão social, ou seja, desenvolvimento (SEN, 2012).

A CF/1988, no art. 170, assentou como pilares da ordem econômica a valorização do trabalho humano e a livre iniciativa, que devem ser aplicados de forma proporcional, a fim de garantir existência digna a todos aqueles que laboram. Da dicção do texto constitucional citado, observa-se que a valorização do trabalho humano precede a livre iniciativa, pelo que esta não pode ser aplicada de forma a ocasionar uma desvalorização do trabalho. Em seguida, na enumeração de princípios, que o legislador constituinte elencou vê-se que a busca pelo pleno emprego é um dos valores que deve ser buscado pela ordem econômica.

Destarte, é possível dessumir que a valorização do trabalho se erige, no texto constitucional, como valor maior do que a livre iniciativa e, inclusive, se sobrepõe à busca pelo pleno emprego, de modo o Brasil assumiu constitucionalmente o compromisso de buscar mecanismos capazes de incluir, em condições de liberdade e igualdade, todos os cidadãos aptos a trabalhar, mas, além disso, comprometeu-se também a garantir trabalho decente, na medida em que elevou a valorização do trabalho humano à categoria de pilar da ordem econômico e um dos pressupostos para a existência digna do ser humano.

No atual momento da conjuntura econômica e política brasileira, as garantias tratadas nesse ponto funcionam como uma muralha cuja finalidade é evitar que o trabalho, em sentido amplo, seja visto, meramente, como um instrumento de criação de valor econômico e seja encarado como um valor social capaz de dignificar o ser humano, gerando inclusão social que repercute sobre todo a coletividade.

\section{A FLEXIBILIZAÇÃO NO DIREITO DO TRABALHO}

O trabalho surge como o mais social dos pactos firmados, considerando o valor social que este possui em sua essência, que transcende às vontades individuais para incorporar o cenário contemporâneo que engloba toda a coletividade, trazendo harmonia e paz social através da inclusão. Por outro lado, o desemprego leva à exclusão social, à redução da qualidade de vida, à baixa estima da pessoa, o surgimento de doenças e a um impacto econômico brutal, haja vista a exclusão das classes sociais segregadas do mercado de consumo.

Contudo, necessário compreender que, por ser o direito um fenômeno social, este carece de renovação constante a fim de manter a sua efetividade, razão porque compreende-se 
que legislação trabalhista no Brasil, oriunda de uma época de transição do modelo de produção fordista para o toyotista, não condiz com as atuais necessidades sociais, carecendo de reformas urgentes, principalmente no que concerne ao modelo clássico de trabalho pautando na subordinação (NASSIF, 2001, p.50).

Tal inadequação do mercado de trabalho, sob a ótica da rigidez das normas trabalhistas, pode ser averiguada pelos dados concretos das pesquisas realizadas pelo IBGE no primeiro trimestre de 2017, no qual o Brasil alcançou uma média de 13,5 milhões de desempregados, 13,2\% de sua população economicamente ativa, maior índice deste o ano de 2012. Mais preocupante ainda é a incrível diminuição dos trabalhadores sob o regime celetista, os quais apresentaram uma queda de 732 mil em relação ao segundo trimestre do mesmo ano, acarretando um crescimento massivo no trabalho informal. (IBGE, 2017)

Essa realidade de crise econômica e desemprego foi vivenciada no continente Europeu na virada do século XXI, momento em que as ideias flexibilizadoras ganharam maior enfoque, como bem esclarece Nascimento (2001, p.63) ao apontar que naquele continente passou-se a admitir um direito do trabalho de crise ou de emergência.

Assim, na perspectiva histórica, Nascimento (2011, p.119) destaca que o protecionismo trabalhista acaba cedendo parcialmente em razão de três paradigmas: as crises econômicas, a redução de custos como meio de enfrentamento da competição empresarial e o avanço tecnológico que permite maior produção com menor número de empregados.

Reconhecendo esse desgaste ideológico do Direito do Trabalho, Delgado (2012, p.111) aponta um novo paradigma alcançado por meio de uma política pública de inclusão social, econômica e até mesmo cultural no âmago da sociedade capitalista.

Nesse sentido, a situação socioeconômica dos últimos tempos, sobretudo em razão do elevado índice de desemprego, gerou algumas alterações em nossa legislação trabalhista, permitindo a flexibilização de determinados institutos. (BELTRAN, 2001, p.154)

O pensamento neoliberal ganhou força, reavivando o postulado da flexibilização para tornar menos rígidas as normas trabalhistas, aumentando a produção, aquecendo a economia e abrindo novos postos de trabalho, o que é refreado pelos agentes sociais que lutam pela manutenção dos direitos dos trabalhadores, reacendendo a antiga luta proletariado $\mathrm{x}$ empresariado.

Certamente, a referida flexibilização e, consequentemente, a modernização do direito do trabalho não pode se limitar a atender exclusivamente os interesses da livre iniciativa e do 
mercado, olvidando-se dos valores socais e do trabalho e garantias fundamentais ao trabalho decente e digno. Nesse sentido, Nelson Manrich (1998, p.45) assim esclarece:

Introduzir uma flexibilização trabalhista com prioridade à empresa, voltada aos valores econômicos, implica considerar apenas o princípio constitucional da livre concorrência e priorizar somente o valor da livre iniciativa, tornando um engodo o valor social do trabalho e a valorização do trabalho humano. Para tanto, o processo de modernização do sistema de relações trabalhistas não pode subordinar-se às prioridades da reforma econômica, ficando a questão social em segundo plano.

O mesmo autor ainda reforça que flexibilizar não é desregulamentar, ou mesmo precarizar direitos, afirmando que "o que se pretende é o ajuste das normas jurídicas à realidade econômica e assim contribuir para a solução dos problemas trabalhistas atuais” (Ibd., p.54)

Em que pese os ensinamentos do autor, notadamente, é preciso entender o trabalho através de uma dinâmica socioeconômica de uma sociedade complexa, pois é necessário compreender o funcionamento da economia nacional a partir do setor empresarial, que, não obstante se encontre do outro lado da tutela laboral, não pode ter ignoradas as suas necessidades, porquanto mantedoras de emprego e, consequentemente, da própria economia. (NASCIMENTO, 2011, p. 117-118)

É necessário realizar a distinção entre a flexibilização e a desregulamentação, institutos que muitas vezes se confundem, mas que nas lições de Garcia (2007, p.83), diferem-se na medida que:

[...] a chamada flexibilização pode ser entendida como forma de amenizar o rigor ou a rigidez de certas normas jurídicas, referentes, no caso, ao Direito do Trabalho. A desregulamentação, por sua vez, refere-se ao fenômeno de se suprimir determinadas normas jurídicas, principalmente estatais, pertinentes à regulação das relações de trabalho, passando os próprios atores sociais a estabelecer a regra aplicável. Nesse sentido, fala-se em desregulamentação negociada do Direito do Trabalho.

Martins (2009, p.15-15), reforçando tal diferenciação, afirma que "na flexibilização deve haver a manutenção de um nível mínimo de legislação, com garantias básicas ao trabalhador e o restante seria estabelecido mediante negociação coletiva. Na flexibilização, há adaptação a um novo contexto econômico."

Feita tal diferenciação e compreendendo o real sentido da flexibilização, vê-se nela um bom mecanismo para a superação das crises econômicas vivenciadas, que quando aplicado conjuntamente a outras medidas destinadas à garantia de direitos laborais - e isso é possível pode-se alcançar uma maior efetividade da tutela laboral. 
Todavia, é preciso ter cuidado com a flexibilização visando tão somente o crescimento econômico e aumento dos postos de trabalho a qualquer custo, eis que incapaz de transpor os desafios socioeconômicos pós-modernos, como nos alerta Souto Maior (2017):

Tais flexibilizações, não podem, portanto, vilipendiar direitos e garantias fundamentais dos trabalhadores, assegurados constitucionalmente e acobertados pelo manto da cláusula pétrea, limitando-se aos espaços cedidos pela própria Constituição, na maioria dos casos através de negociação sindical, sem que isso seja, necessariamente, considerado precarização do emprego. (ZENNI \& OLIVEIRA, 2008, p.82).

Assim, a flexibilização, não obstante aparentemente contrária ao protecionismo trabalhista, deve ser avaliada e contemplada sob o prisma dos direitos e garantias fundamentais, como forma de assegurar o pleno emprego, a função social do trabalho e diversos direitos sociais, pois o direito do trabalho sempre deve pautar-se na justiça social.

\section{A TEORIA DA FLEXISECURITY E A GARANTIA DO TRABALHO EM TEMPOS DE CRISE}

\subsection{O Surgimento da Teoria da Flexisecurity}

Como visto, por muito tempo a flexibilização foi uma bandeira levantada pelo empresariado que sustenta a necessidade de modernização do direito do trabalho, alegando que o protecionismo elevado da legislação onera e dificulta o desenvolver da atividade produtiva, principalmente em tempos de crise econômica.

Tal intento era frontalmente barrado pelos que advogam a manutenção dos direitos trabalhistas, que se revestem da natureza de direito fundamental, e, consequentemente, não admitem retrocesso, eis que provindos das conquistas histórias e da luta da classe proletária por melhores condições de trabalho.

A fim de superar esse conflito e apontar uma solução para as dificuldades econômicas existentes no continente Europeu, especialmente o desemprego que estagnou a economia naquela região, surgiu na Dinamarca e na Holanda a teoria da flexisecurity, a qual "pretende conciliar dois valores sensivelmente antagônicos, quais sejam a flexibilidade do mercado de trabalho e a segurança dos trabalhadores contra o desemprego" (DELLEGRAVE NETO, 2008, p.25). 
Esse diálogo entre flexibilidade e segurança foi inicialmente proposto através da facilitação da contratação e dispensa da mão de obra, atrelado a reciclagem profissional por meio de políticas públicas de reinserção no mercado de trabalho e medidas de bem-estar social (Welfere State), balanceando-se, assim, os interesses do mercado com a garantia ao trabalho e valorização do ser-humano.

Da própria terminologia da palavra flexisecurity ou flexisegurança extrai-se o conceito do instituto, que busca formas de flexibilização de normas trabalhistas - a fim de revitalizar a atividade empresarial e o mercado de trabalho -, assegurando, em contrapartida, segurança jurídica aos trabalhadores através da manutenção de garantias fundamentais e direitos sociais

Nessa perspectiva, a flexisecurity apresenta-se como uma teoria de centro, inserindose entre a desregulamentação do mercado de trabalho e a rigidez das normas atuais, na busca de uma "fórmula mágica", que incorpora o melhor dos dois mundos através de uma série de medidas pautadas na harmonização dos interesses do mercado - capital - e dos trabalhadores. (VIEBROCK, CLASEN, 2009, apud, REZENDE FILHO, 2013)

Nesse sentido, o professor holandês Wilthangen (2004, p.5) da universidade de Tilburg, traz o conceito da flexisecurity como:

\footnotetext{
A estratégia política que tenta, de forma sincronizada e deliberada, aprimorar a flexibilidade dos mercados de trabalho, da organização do trabalho e das relações de trabalho por um lado e aprimorar a segurança - a segurança da empregabilidade e segurança social - notadamente para grupos mais fracos de trabalhadores, tanto aqueles dentro como aqueles fora do mercado de trabalho, por outro lado.
}

Por outro lado, Burchel (2008, p.3) aponta a dificuldade de se conceituar a flexisecurity, mas reconhece que tais medidas trazem benefícios econômicos e sociais, em razão da possibilidade de adaptação do mercado às novas tecnologias e a redução do desemprego e dos efeitos deletérios desse nos períodos de transição entre empregos, reduzindo a pobreza e, especialmente, a incerteza de relocação no mercado.

Tal teoria vem, portanto, no escopo de incorporar os preceitos supostamente antagônicos da flexibilização e da garantia aos direitos fundamentais do trabalhador, buscandose uma solução para a crise econômica por meio da retomada do trabalho como fator de desenvolvimento pela criação de novos postos de trabalho formais.

Contudo, o trabalho não pode ser entendido como um fim em si mesmo, mas como forma de alcançar condições de vida digna, através da garantia ao pleno emprego, ao trabalho 
decente e à satisfação pessoal do trabalhador, o que estimula um desenvolvimento socioeconômico sustentável por meio da inclusão social-democrática das classes excluídas.

Relembra-se, assim, que a flexibilização incorporada na teoria da flexisecurity deve ser aquela apontada no tópico anterior, que não se confunde com desregulamentação de direitos, mas sim mostra uma face flexível do direito do trabalho, pronta a se adaptar à realidade econômica e social porque passa determinada sociedade em determinado momento histórico.

Nesse contexto, destaca-se que a experiência nórdica de flexisegurança foi considerada um sucesso, com a redução abrupta do desemprego e elevação do crescimento econômico e social, através de incentivos financeiros no mercado e garantais sociais aos trabalhadores, que naquela oportunidade ocorreu através de incentivos fiscais e assistencialismo estatal para os desempregados, seguidos de cursos de capacitação e reinserção no mercado de trabalho.

Essas medidas, focadas na revisão do Direito do Trabalho em razão da redução e segmentação do mercado de trabalho, ocorreram tanto de forma interna - na organização do trabalho, horário e atribuições-, quanto externa - atenuando a quantidade de funcionários e as formas de contratações, como bem aponta Rodriguez (2008, p.10 - 11).

A partir do "Livro Verde" apresentado em 2006 e cujo lema era "modernizar o Direito do Trabalho face aos desafios do século XXI", trouxe-se ao debate a modernização do Direito do Trabalho na União Europeia, dando cumprimento aos objetivos da "Estratégia de Lisboa" de conseguir um desenvolvimento sustentável pautado no trabalho, utilizando-se de substrato as teorias flexibilizadoras, principalmente, a flexisegurança.

Esse manifesto concluiu que as formas contratuais atípicas - que vieram a ser posteriormente reguladas por medidas de flexisecurity - já existiam independentemente de regulamentação legal, principalmente, em face da necessidade de adaptação do mercado de trabalho e do desenvolvimento da organização do trabalho e da sociedade Europeia, que necessitava de um novo direcionamento econômico mais inclusivo. Por outro lado, importante frisar que o mesmo relatório já advertia dos perigos da flexibilidade e os seus efeitos sobre a qualidade do trabalho, principalmente quando realizada sem a devida proteção social. (COMMISSION OF THE EUROPEAN COMMUNITIES, 2006, p.3)

Não obstante as medidas de modernização do trabalho estivessem já em comento no ano de 2006 na União Europeia, tão somente com a grave crise econômica que se alastrou pelo continente em meados de 2011 é que estas medidas foram aplicadas de maneiras mais enérgica. 
Analisando o modelo Dinamarquês, Rezende Filho (2013, p.77), afirma que nesse berço da teoria em análise, constituiu-se uma relação tríplice entre a flexibilidade, a segurança e políticas públicas de mercado. Foi tão flexibilizada a contratação e dispensa de trabalhadores naquele país que chegou-se a $25 \%$ a rotatividade anual dos empregados em seus postos, sendo, por outro lado, ofertado um sistema sólido de seguro desemprego, o qual garante até $90 \%$ da remuneração do trabalhador, que, atrelado às políticas públicas de reinserção no mercado de trabalho, com investimentos correspondentes a 1,5\% do Produto Interno Bruto do país, (REZENDE FILHO, 2013) o que fez a taxa de desemprego cair quase $2 \%$ entre os anos de 2012 e $2016^{5}$.

Romita (2008, p.44), observando os efeitos das primeiras medidas tomadas pelo governo dinamarquês para superação da crise econômica, já destacava:

O bom êxito do modelo dinamarquês é atribuído pelos especialistas a uma combinação extraordinária de flexibilidade da relação de trabalho e da segurança econômica e social dos empregados. Os trabalhadores não contemplados pelo sistema de prestação por desemprego estão cobertos por um sistema de desemprego e por prestações de previdência social custeadas principalmente pelo Estado.

Ademais, tais medidas de flexisegurança foram utilizadas por diversos países Europeus, a exemplo da Espanha, que procurou regular os contratos por prazo determinado, muitas vezes por meio de negociação coletiva e da intervenção de agencias de empregos, principalmente nos contratos temporários e autônomos, que passaram a gozar de uma proteção mínima de trabalho. Nesse país foi aplicado o denominado "sistema conjuntural de contratação a prazo", que procurava fomenta a criação de postos de trabalho a fim de circular a renda e movimentar a economia, que se encontrava estagnada em razão do elevado desemprego. Importante esclarecer que após a superação da crise pelo aumento do trabalho e circulação de renda, a Espanha buscou controlar e reduzir os trabalhos temporários, principalmente através de planos de incentivo aos contratos por prazo indeterminado, demonstrando, assim, que as medidas de flexisegurança tomadas naqueles país foram efetivas, mas, após alcançada a estabilidade econômica, devem ser atenuadas.

Outro país que teve larga utilização das medidas de flexisecurity foi a Holanda, onde Rezende Filho (2013. P.79) afirma que houve a regulamentação das formas contratuais atípicas - aquelas se afastam do contrato de trabalho por prazo indeterminado - através de negociações

\footnotetext{
${ }^{5}$ Dados disponíveis em http://ec.europa.eu/eurostat/en/web/lfs/statistics-illustrated
} 
coletivas e normas legais que garantem direitos sociais, tais quais previdência e salário mínimo, aos trabalhadores autônomos e temporários, o que fomenta a flexibilização e, ao mesmo tempo, assegura melhores condições de trabalho para tais profissionais.

Percebe-se assim, por meio desses exemplos e de outros tantos países - os quais não seria possível apontar nesse artigo -, a grande força da onda flexibilizadora na União Europeia nas últimas décadas, que revela uma grande preocupação com a garantia de trabalho em detrimento da segurança no mesmo emprego, favorecendo-se a circulação da mão-de-obra e sua rotatividade, fomentando, concomitantemente, a capacitação dos profissionais que se encontram fora do mercado para que esses encontrem novo posto de trabalho rapidamente, enquanto gozam do benefício assistencial, sem que isso lhes cause prejuízos econômicos e, consequentemente, sociais.

Em que pese tais benefícios econômicos e a inquestionável redução do desemprego nos países europeus, tais medidas sofreram graves críticas sob o argumento de que a flexisecurity estaria mais preocupado com termo "flexi" do que propriamente com a segurança dos trabalhadores, sendo, na realidade, um conjunto de medidas econômicas que buscam o interesse do mercado em detrimento das condições de trabalho e manutenção do trabalho.

Em todo caso, considerando que as medidas de flexisegurança são - e devem ser estudadas de acordo com a realidade social e histórica do país na qual elas estejam sendo aplicadas, é necessário compreender o cenário atual do Brasil para melhor entender como as medidas flexibilizadoras podem ser e estão sendo aplicadas na realidade brasileira.

\subsection{Flexisecurity no Direito Brasileiro: Possibilidade ou Realidade?}

Em primeiro lugar, é necessário apontar que a crise econômica que imobilizou a União Europeia em meados de 2011 - fruto do endividamento público de alguns países como Portugal, Grécia e Espanha, ocasionando a fuga de investidores e, consequentemente, a diminuição da produção e do trabalho - não atingiu com grandes consequências o Brasil naquela época.

A crise econômica que atualmente é vivida pelo Brasil deu os seus primeiros sinais em meados de 2014, atrelada a baixa do valor das commodities no mercado internacional e agravada pela crise política decorrente da perda da governabilidade em razão dos escândalos da corrupção. O novo Governo entende que a crise de postos de trabalho deve ser afrontada 
com reformas estruturais, que serão capazes de afrontar o cenário recessivo da economia nacional, que contraiu aproximadamente $4 \%$ (quatro por cento) durante os últimos anos, nos quais se alcançou taxas de desemprego de 11,8\%. (IBGE, 2015)

Nesse cenário, foi proposto pelo Presidente Michel Temer a Reforma Trabalhista (Projeto de Lei 6.787/16), aprovada na Câmara dos Deputados no dia 27 abril de 2017, chegando ao Senado Federal (tramitando como PLC 38/2017) no dia seguinte, sendo votada e aprovada pelo conjunto dos senadores em 11 de julho, sancionada pelo Presidente da República no dia 13 de julho de 2017 e passando a ter vigor logo após 120 dias da sanção presidencial.

A referida reforma possui como ponto nodal a elevação da autonomia da vontade do trabalhador, coletiva e individual, podendo diversos direitos serem negociados - na maioria dos casos mediante instrumento coletivo-, tais como parcelamento de férias; jornada de trabalho, desde que respeitado o limite de 12 horas diárias e 220 horas mensais; intervalo intrajornada; plano de cargos e salários; entre outros. Também foi objeto da reforma os contratos de trabalho temporário - os quais tiveram os prazos elastecidos e abertos à possibilidade de contratação direta-, e o regulação do contrato de trabalho intermitente e do home office, entre outras muitas alterações que não serão aqui citadas por não se tratar do objeto principal do presente estudo.

Notadamente, percebe-se que grande parte da Reforma Trabalhista (Lei $n^{\circ}$ 6.787/16) se sustenta e consagra na autonomia da vontade coletiva, ou seja, nas negociações flexibilizações - realizadas entre sindicatos patronais e sindicatos dos trabalhadores, ou mesmo com o representante dos trabalhadores nas grandes empresas. Nesses casos, Crepaldi (2003, p.69-70) entende que estar-se-ia respeitando, através desses acordos coletivos, tanto a autonomia privada quanto a coletiva, eis que realizado por um negócio jurídico perfeito, sendo possível a regulação/flexibilização dos direitos trabalhistas, desde que, claro, sejam assegurados os direitos fundamentais mínimos.

Nesse sentido, Sarlet (2007, p.417 - 418), tratando da importância da imutabilidade de direitos fundamentais, afirma que tais direitos abrangeriam todos os direitos sociais, inclusive os direitos possuídos pelos trabalhadores e elencados no art. $7^{\circ}$, da Constituição Federal da República de 1988. E continua o autor esclarecendo que:

[...]se por um lado a imutabilidade gera riscos no tocante ao atraso com relação as mudanças ocorridas na sociedade, também a garantia de certos conteúdos essenciais é necessária para que haja segurança jurídica e proteção aos casuísmos da política e das maiorias parlamentares. 
Relembra-se assim que o mencionado art. $7^{\circ}$ do texto constitucional está localizado no capítulo referente aos direitos sociais e trata dos direitos dos trabalhadores urbanos e rurais, sendo, inquestionavelmente, considerados direitos fundamentais. Nesse viés, a flexibilização e consequente retirada de tais direitos de um patamar constitucional imutável acarretaria um retrocesso social, o que é vedado no ordenamento jurídico Brasileiro.

Por conseguinte, ao equiparar os direitos dos trabalhadores com direitos fundamentais, percebe-se a preocupação do constituinte com a proteção social do trabalhador, conferindo patamares mínimos de dignidade no trabalho que não podem ser maleabilizados pelas correntes flexibilizadoras, sob pena de não se estar contemplando o valor social do trabalho, a dignidade humana do trabalhador e, consequentemente, alcançado o ideal do trabalho decente.

Qualquer flexibilização de direitos sociais deve estar, portanto, necessariamente vinculada e limitada ao texto Constitucional, o que, em relação aos direitos trabalhistas, encontram-se exatamente no art.7º, VI, XIII e XIV, da Constituição Federal do 1988.

Assim, surge o grande embate no cenário jurídico atual sobre a (in)constitucionalidade da Reforma Trabalhista (Lei ${ }^{\circ}$ 6.787/1), eis que versa sobre várias flexibilizações que vão além daquelas possibilidades encontradas no texto constitucional, tais como a possibilidade de trabalhadores intermitentes, os quais receberão por hora de serviço efetivamente prestado, a chamado do empregador, retirando-lhes qualquer segurança sobre a quantia mínima que receberão em cada mês trabalhado, o que violaria em tese o princípio da segurança e certeza que regem os contratos trabalhistas.

Outro grande ponto de debate acerca da (in)constitucionalidade da referida Lei recai sobre a terceirização das atividades fim, instituto que muitos entendem quebrar a pessoalidade da relação laboral, coisificando o ser-humano trabalhador, tornando-o mero objeto no processo produtivo, indo de encontro a com a valorização do trabalho humano e o pleno emprego assegurados pelo art. 170, da Constituição Federal de 1988.

Apontando tais irregularidades, o Ministério Público do Trabalho da $2^{\mathrm{a}}$ Região - São Paulo - elaborou estudo sobre a (in)constitucionalidade da norma em apreço, publicado em seu site institucional, concluindo que a Reforma Trabalhista, além de inconstitucional, não fomentará a criação de novos empregos, ou seja, não combaterá o desemprego mas tão somente precarizará as relações trabalhistas. Aponta a existência de um Estudo da Organização Internacional do Trabalho (OIT), "Emprego mundial e perspectivas sociais 2015: a natureza cambiante do trabalho", em que foram analisados dados e estatísticas de 63 países, concluindo 
que, nos últimos 20 anos, a diminuição na proteção dos trabalhadores não estimulou a criação de empregos, não sendo capaz de reduzir a taxa de desemprego. ${ }^{6}$

Em que pese todo o embate acerca da constitucionalidade da referida Lei, ou mesmo da sua efetividade enquanto fator de superação da crise econômica por meio do trabalho, o fato é que as medidas flexibilizadoras estão em pauta no cenário político na realidade atual do Brasil, que carece de estudos mais aprofundados na área, seja no âmbito jurídico o econômico.

Nesse viés, é importante relembrar que Romita (2008, p. 10), bem antes do crescimento da onda flexibilizadoras, já considerava inevitável a solidificação desse movimento, eis que apesar de muitos estudiosos enfrentarem tal fenômeno, primando pela manutenção dos direitos sociais, a flexibilização operaria seus efeitos independentemente da manifestação doutrinária, por ser fruto de transformações políticas e econômicas, haja vista que o Direito do Trabalho, com em qualquer outro ramo do Direito, deve acompanhar as mudanças e necessidades sociais.

Isso nos revela que as relações de trabalho, por fim, acabam se modificando - muitas vezes de forma flexível - antes mesmo de existir legislação que as regule, a exemplo de diversas modalidades contratuais que hoje, por ausência de regulamentação legal, são tratadas como trabalhos informais, deixando à margem da proteção diversos trabalhadores que sequer possuem seus direitos sociais básicos protegidos.

Nessa perspectiva, é muito interessante relembrar que o direito do trabalho é diretamente relacionado com estabilidade da economia de determinada sociedade. Isso pode ser esclarecido por meio da metáfora do "Pêndulo", ou seja, quando se vivencia tempos de economia fortalecida - mesmo quando essa não está igualmente distribuída-, os direitos sociais tendem à profusão, por outro lado, em tempos de déficit econômico, os direitos sociais tendem à contração.

Nessa esteira de pensamento Nascimento (1993, p.35) afirmava que:

(...) o trabalho, no mundo moderno, é um valor fundamental, sofre o impacto direto
dos acertos ou desacertos econômicos de um país, que refletem sobre as relações de
trabalho, favorecendo-as ou penalizando. O direito do trabalho é expressão do
humanismo jurídico e arma de renovação social pela sua total identificação com as
necessidades e aspirações concretas do grupo social durante os problemas na questão
social. Representa uma atitude de intervenção jurídica, par a restauração das
instituições sociais e para melhor relacionamento entre o homem que trabalha e
aqueles os quais o trabalho é destinado"

${ }^{6}$ International Labour Organization, World employemente and social outlook. Geneva: ILO, 2015, p.15, Disponível em: <http://www.prt2.mpt.mp.br/419-estudo-aponta-que-reforma-trabalhista-e-inconstitucional> Acesso em 06 de Ago. de 2017 
Dessa maneira, certamente é preciso pensar e estudar o direito do trabalho de forma atual e buscando uma maior proteção do trabalhador em lato sensu, inclusive com novas formas de contrato de trabalho que não sejam caracterizadas tão somente pelo trabalhador empregado, sem, contudo, precarizar a relação de emprego srticto sensu vilipendiando direitos já adquiridos.

Enfim, buscar encontrar o ponto de equilíbrio entre a defesa dos direitos sociais e a reais necessidades indispensáveis à dinâmica do mercado torna-se a grande dificuldade e missão dos Estados, em uma época em que a evolução tecnológica e a globalização se apresenta como um processo irreversível. (BAUMAN, 1999, p.5)

\section{CONSIDERAÇÕES FINAIS}

O trabalho se apresenta como importante fator desenvolvimento social e econômico, através do qual o homem busca sua dignificação e inclusão na sociedade, constituindo o seu fomento uma tarefa árdua a ser efetivada pelo Estado, que muitas vezes é atravancada por períodos de recessão econômica e alto índice de desemprego.

Em tempos de crise, o debate em prol da flexibilização dos direitos trabalhistas ressurge, sob o pretexto de que a rigidez e protecionismo do direito do trabalho se tornam um entrave ao desenvolvimento econômico, dificultando a superação da crise e interferindo diretamente no aumento das taxas de desemprego e, consequentemente, pobreza.

Contudo, é preciso ter em mente que a limitação econômica não pode sacrificar o avanço dos direitos sociais historicamente alcançados, que acarreta uma penalização para a parte mais frágil da relação trabalhista e permite o retrocesso em direitos sociais, o que é vedado no ordenamento jurídico brasileiro.

Nesse contexto, a teoria da flexisecurity, nascida no direito comparado especificamente no Norte Europeu - apresenta-se justamente no intento de amparar as necessidades e anseios antagônicos do mercado e da classe trabalhadora, lançando medidas que, por um lado, flexibilizam as normas trabalhista em prol da criação de empregos, mas, por outro, confere segurança e proteção aos trabalhadores. Muito embora a proposta seja de balancear tais interesses, grande é a preocupação em relação a forma como tais medidas serão aplicadas, 
precipuamente em razão do perigo de que estas atendam de maneira desigual aos interesses do capital em detrimento de condições dignas e decentes de trabalho.

De toda sorte, salienta-se que a flexibilização, por se tratar de uma bandeira levantada principalmente em tempos de crise econômica e desemprego, reflete a necessidade do mercado de trabalho se adaptar à realidade atual da sociedade, através da atividade estatal - executiva e legislativa - por meio de políticas públicas e reformas estruturais na legislação vigente.

No Brasil, destaca-se a Reforma Trabalhista proposta pelo Governo Michel Temer (Lei ${ }^{\circ}$ 6.787/16), a qual reestrutura diversos aspectos da relação laboral no país, inclusive, regulamentando formas contratuais atípicas, tais como contratos temporários e intermitentes. Tal Reforma, em que pese o trâmite de urgência no Congresso Nacional, foi aprovada e terá vigência a partir de novembro de 2017 , razão porque é de se apontar que a flexibilização, no Brasil, passa a ser uma realidade, sobre a qual deve-haver maiores estudos.

Em todo caso, cumpre relembrar que, em falando de flexibilização de normas trabalhistas, devem sempre ser respeitados os postulados da valorização do trabalho humano e da sua dignidade, do valor social do trabalho, do pleno emprego, entre tantos outros princípios fundamentais que direcionam o direito para proteção do ser-humano, e não do capital, sem, contudo, olvidar que a dinâmica do mercado por diversas vezes precisa de normas flexíveis para o seu desenvolvimento, capazes de acompanhar as necessidades das cadeias produtivas e das relações sociais.

Por certo que os caminhos para superar os cenários de crise econômica são complexos e difíceis, mas sempre devem rumar no sentido de buscar a harmonização entre o trabalho e o capital, realizado por meio do diálogo entre a necessidade protetora dos hipossuficientes e a coordenação dos interesses de mercado que precisam de dinamismo para continuar evoluindo. Essa interlocução desses pontos antagônicos é a proposta da flexisecurity, que busca compor as necessidades de ambos.

\section{REFERÊNCIAS}

ÁVILA, Humberto. Teoria dos princípios. 11 ed. São Paulo: Malheiros, 2010.

BARCELLOS, Ana Paula. A eficácia jurídica dos princípios: o princípio da dignidade da pessoa humana 2 ed. Rio de Janeiro: Renovar, 2008. 
BAUMAN, Zygmunt. Globalização: As consequências humanas. Rio de Janeiro: Jorge Zahar Editor, 1999.

BURCHELL, Brendan. Can flexisecurity reduce the relationship between job insecurity and pychological well-being? Cambridge. OIT. 2008. Disponível em: <http://www.ilo.org/wcmsp5/groups/public/---ed_protect/---protrav/---

travail/documents/meetingdocument/wcms_123864.pdf >. Acesso em: 27 de julho de 2017

BRASIL. Constituição da República Federativa do Brasil de 1988. Disponível em: <http://www.planalto.gov.br/ccivil_03/constituicao/constituicaocompilado.htm>. Acesso em: 21 de maio de 2017

BRASIL. Decreto-Lei $n^{\circ} 5452$ de $1^{\circ}$ de maio de 1943. Aprova a Consolidação das Leis do Trabalho. Disponível em: <http://www.planalto.gov.br/ccivil_03/decreto-lei/del5452.htm>. Acesso em: 21 de maio 2017.

CANOTILHO, José Joaquim Gomes. Direito Constitucional e Teoria da Constituição. 7 ed. Coimbra: Almedina, 2004.

COMMISSION OF THE EUROPEAN COMMUNITIES. GREEN PAPER: Modernising Labour Law to Meet the Challenges of the $21^{\text {st }}$ century. Brussels, 2006. Disponível em em: <http://www.europarl.europa.eu/meetdocs/2004_2009/documents/com/com_com(2006)0708 lcom_com(2006)0708_en.pdf>. Acesso em: 03 de junho de 2017.

CREPALDI, Joaquim Donizeti. O princípio de Proteção e a Flexibilização das normas de Direito do Trabalho. São Paulo: LTr, 2003

DELGADO, Maurício Godinho. Curso de Direito do Trabalho. 11 ed. São Paulo: LTr, 2012.

IBGE. Pesquisa Industrial Mensal: emprego e salário. Disponível em: ftp://ftp.ibge.gov.br/Industrias_Extrativas_e_de_Transformacao/Pesquisa_Industrial_Mensal_ de_Emprego_e_Salario/Comentarios/pimes_201512comentarios.pdf $>$. Acesso em: 13 de agosto de 2017.

LEDUR, José Felipe. A realização do direito ao trabalho. Porto Alegre: Sérgio Antônio Fabris, 1998.

LEITE, Carlos Henrique Bezerra. Curso de direito processual do trabalho. $8^{\mathrm{a}}$ ed. São Paulo: LTr, 2010.

MARTINS, Sergio Pinto. Flexibilização das Condições de Trabalho. 4 ed. São Paulo: Atlas, 2009.

NASCIMENTO, Amauri Mascaro. Direito Contemporâneo do Trabalho. São Paulo: LTr, 2011.

NASCIMENTO, Amauri Mascaro. Iniciação ao Direito do Trabalho. 27 ed. São Paulo: LTr, 2001. 
NASCIMENTO, Amauri Mascaro. Mudanças no Mercado de Trabalho. In RODRIGUES, Aluísio (Coord). Direito Constitucional do Trabalho. São Paulo: LTr, 1993, p. 35-50.

OIT. Trabajo decente y la Agenda 2030 para el Desarrollo Sostenible. Genebra, 2017. Disponível em: http://www.oit.org/wcmsp5/groups/public/---dgreports/--dcomm/documents/publication/wcms_470340.pdf. Acesso em: 04 de agosto de 2017.

OIT. Convenção $\mathbf{n}^{\mathbf{1}}$ 122. Genebra, 1965. Disponível em: <http://www.oitbrasil.org.br/node/479>. Acesso em: 03 de agosto de 2017.

ONU. Agenda 2030 para el desarrolho sostenible. Nueva York, 2015. Disponível em: <http://www.un.org/es/comun/docs/?symbol=A/RES/70/1 >. Acesso em: 04 de agosto de 2017.

REZENDE FILHO, Tabajara Medeiros. Do Protecionismo do Empregado à Proteção do Trabalhador: Desafios da Flexisecurity. São Paulo: USP. 2013. 160f. Tese de Doutorado Faculdade de Direito da Universidade de São Paulo. Disponível em: < file:///C:/Users/Flávia\%20de\%20Paiva/Downloads/tese_Tabajara_Medeiros_de_Rezende_Fil ho\%20(1).pdf>. Acesso em: 13 de agosto de 2017.

ROMITA, Arion Sayão. Flexigurança: a reforma no mercado de trabalho. São Paulo: LTr, 2008

SARLET, Ingo Wolgang. Dignidade da Pessoa Humana e Direitos Fundamentais na Constituição Federal de 1988. 5 ed. Porto Alegre: Livraria do Advogado, 2007.

SCHIAVI, Mauro. Execução no Processo do trabalho. São Paulo: LTr, 2008.

SOUTO MAIOR, Jorge Luiz. Direito do Trabalho e Desenvolvimento Econômico - um contraponto à teoria da flexibilização. Disponível em: <http://www.jorgesoutomaior.com/uploads/5/3/9/1/53916439/direito_do_trabalho_e_desenvo lvimento_econ\%C3\%94mico..pdf >. Acesso em: 10 de agosto de 2017. 